\title{
Vigorous Motor Activity in Caenorhabditis elegans Requires Efficient Clearance of Dopamine Mediated by Synaptic Localization of the Dopamine Transporter DAT-1
}

\author{
Paul W. McDonald, ${ }^{1 \star}$ Shannon L. Hardie, ${ }^{1 *}$ Tammy N. Jessen, ${ }^{1}$ Lucia Carvelli, ${ }^{1}$ Dawn Signor Matthies, ${ }^{1}$ and \\ Randy D. Blakely ${ }^{1,2,3}$ \\ Departments of ${ }^{1}$ Pharmacology and ${ }^{2}$ Psychiatry and ${ }^{3}$ Center for Molecular Neuroscience, Vanderbilt University School of Medicine, Nashville, Tennessee \\ $37232-8548$
}

\begin{abstract}
The catecholamine dopamine (DA) functions as a powerful modulatory neurotransmitter in both invertebrates and vertebrates. As in man, DA neurons in the nematode Caenorhabditis elegans express a cocaine-sensitive transporter (DAT-1), presumably to regulate synaptic DA signaling and limit DA spillover to extrasynaptic sites, although evidence supporting this is currently lacking. In this report, we describe and validate a novel and readily quantifiable phenotype, swimming-induced paralysis (SWIP) that emerges in DAT-1deficient nematodes when animals exert maximal physical activity in water. We verify the dependence of SWIP on DA biosynthesis, vesicular packaging, synaptic release, and on the DA receptor DOP-3. Using DAT-1 specific antibodies and GFP::DAT-1 fusions, we demonstrate a synaptic enrichment of DAT-1 that is achieved independently of synaptic targeting of the vesicular monoamine transporter (VMAT). Importantly, dat-1 deletions and point mutations that disrupt DA uptake in cultured C. elegans neurons and/or impact DAT-1 synaptic localization in vivo generate SWIP. SWIP assays, along with in vivo imaging of wild-type and mutant GFP::DAT-1 fusions identify a distal $\mathrm{COOH}$ terminal segment of the transporter as essential for efficient somatic export, synaptic localization and in vivo DA clearance. Our studies provide the first description of behavioral perturbations arising from altered trafficking of DATs in vivo in any organism and support a model whereby endogenous DA actions in C. elegans are tightly regulated by synaptic DAT-1.
\end{abstract}

Key words: dopamine; transporter; receptor; C. elegans; dat-1; synapse; localization; PDZ binding domain; unc-104; cat-1

\section{Introduction}

The catecholamine dopamine (DA) modulates both excitatory and inhibitory synaptic signaling (Dani and Zhou, 2004; Seamans and Yang, 2004) and in man plays a critical role in forebrain circuits implicated in motor and cognitive disorders (Reimherr et al., 1984; Crossman et al., 1987; Hernandez and Hoebel, 1988; Fiorino et al., 1993; Carlsson et al., 2004). An important mechanism of DA inactivation involves reuptake of DA by the presynaptic DA transporter (DAT) (Gainetdinov et al., 1998; BenoitMarand et al., 2000). Mice lacking DAT (Giros et al., 1996) exhibit profound neurochemical changes including elevated extracellular levels of DA, prolonged DA clearance, and diminished levels of intraneuronal DA. Behaviorally, these mice display hyperactivity, cognitive deficits, and altered psychostimulant re-

\footnotetext{
Received July 1, 2007; revised 0ct. 16, 2007; accepted Nov. 13, 2007.

This work was supported by National Institutes of Health Awards NS046237 (P.W.M.), MH065782 (S.L.H.), MH58921 (T.N.J., L.C.), and MH073159 and DA014917 (R.D.B.). Some of the strains used in this work were provided by the Caenorhabditis Genetics Center, which is funded by the National Institutes of Health Center for Research Resources. We thank Jane Wright, Angela Steele, and Qiao Han for general laboratory support, Ana Zhu for assistance with imaging efforts, Paul A. Fleming for assistance with nematode thrashing assays, and Louis J. DeFelice and Aurelio Galli for helpful discussions.

*P.W.M. and S.L.H. contributed equally to this work.

Correspondence should be addressed to Dr. Randy D. Blakely, Suite 7140, MRB III, Center for Molecular Neuroscience, Nashville, TN 27232-8548. E-mail: randy.blakely@vanderbilt.

DOI:10.1523/JNEUROSCI.2992-07.2007

Copyright $\odot 2007$ Society for Neuroscience $\quad$ 0270-6474/07/2714216-12\$15.00/0
}

sponses (Gainetdinov et al., 2002; Hironaka et al., 2004; Powell et al., 2004; Rodriguiz et al., 2004; Medvedev et al., 2005; Tillerson et al., 2006).

Mammalian DA neurons express different levels of DAT (Lorang et al., 1993; Nirenberg et al., 1997a,b; Ciliax et al., 1999) and DAT proteins are subject to multiple modes of regulation (for review, see Melikian, 2004), influencing the degree to which DA participates in synaptic versus extrasynaptic signaling (Miles et al., 2002). In vitro studies suggest important roles for DAT $\mathrm{COOH}$ terminal sequences in establishing appropriate surface expression and DA transport (Torres et al., 2001; Carneiro et al., 2002; Bjerggaard et al., 2004; Miranda et al., 2004; Holton et al., 2005), although whether these elements function in vivo is unknown. To explore the relationship between DAT expression and localization and DA signaling in vivo, we have capitalized on the presence of a DAT ortholog [DAT-1 (Jayanthi et al., 1998)] in the powerful model system Caenorhabditis elegans (Nass et al., 2002, 2005). DA neurons in C. elegans were first identified on the basis of histofluorescence (Sulston et al., 1975) and confirmed by expression of genes for DA biosynthesis (Lints and Emmons, 1999), storage (Duerr et al., 1999) and inactivation (Jayanthi et al., 1998).

The functions of endogenous DA in C. elegans have been inferred using laser ablation of DA neurons, through genetic manipulations of DA-related genes, and through the treatment of 
worms with exogenous DA (Sawin et al., 2000) (see also McDonald et al., 2006). These studies implicate DA signaling in egg-laying, defecation, basal motor activity, sensation/response to food sources, and habituation to touch (for review, see McDonald et al., 2006). Recent nematode studies suggest that DA can also signal extrasynaptically (Chase et al., 2004), raising questions as to the function of DAT-1 in vivo. Here, we define a behavioral phenotype, swimming-induced paralysis (SWIP), that is dependent on endogenous DA release as well as synaptic DAT-1 trafficking and function. Through SWIP assays and the visualization of fluorescent DAT-1 fusion proteins, we provide evidence that DAT-1 constrains DA spillover that negatively regulates the motor program through the DA receptor DOP-3 and identify a role for the distal DAT COOH terminus in DAT-1 synaptic localization.

\section{Materials and Methods}

\section{C. elegans strains and husbandry}

C. elegans strains were cultured on bacterial lawns of OP50 or NA22 and maintained at $14-20^{\circ} \mathrm{C}$ using standard methods (Brenner, 1974). The wild-type strain is N2 Bristol. unc-104(e1265)II, mod-5(n3314)I, cat2(e1112)II, dop-1(vs100)X, dop-2(vs105)V, dop-3(vs106)X, and dop4(ok1321)X were obtained from the Caenorhabditis Genetics Center (University of Minnesota, Minneapolis, MN). The dat-1 (ok157)III strain was a gift from J. Duerr and J. Rand (Oklahoma Medical Research Foundation, Oklahoma City, OK), which is a complete loss of function mutation that eliminates the majority of the DAT-1 coding sequence. Strains bearing the EMS-generated dat-1 mutations BY298 (dat- $1_{G 55 E}(v t 2)$;

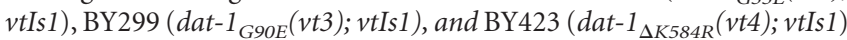
were described previously (Nass et al., 2005). Double mutants were created by crossing dat-1(ok157)III males with cat-2(e1112)II, dop1(vs100)X, or dop-3(vs106)X hermaphrodites. C. elegans genomic DNA was obtained as described previously (Nass et al., 2005) and used at a concentration of $1 \mathrm{ng} / \mu \mathrm{l}$ to determine the genotype of lines after husbandry experiments (all oligonucleotides are described in supplemental Table 1, available at www.jneurosci.org as supplemental material). Double mutant lines were first screened using single worm PCR (Barstead et al., 1991; Williams et al., 1992) with oligos directed at dat-1 (ok157)III and then further analyzed using oligos specific to the second gene of interest.

\section{DAT-1 antibody production and immunofluorescence}

Antibody production. Polyclonal antibodies were generated against a glutathione-s-transferase (GST) fusion protein fused to the DAT-1 intracellular $\mathrm{COOH}$ terminus. cDNA was amplified from full-lengthdat-1 cDNA, cloned into pGEX5x3 expression vectors and expressed in BL21(DE3) cells. IPTG induction and protein purification were performed as previously described (Ferguson et al., 2003), except that purified extract was run on an SDS-PAGE gel and the full-length fusion protein was extracted by gel electro-elution. The resultant purified fulllength fusion protein was dialyzed to a final concentration of $1 \mathrm{mg} / \mathrm{ml}$ and used for immunization into rabbits (Prosci, San Diego, CA).

Immunocytochemistry. To analyze the specificity of the DAT-1 antibody, HEK-293T cells were plated at 60,000 cells/dish in $\gamma$-irradiated 35 $\mathrm{mm}$ glass bottom microwell poly-D-lysine coated dishes (MatTek, Ashland, MA) and allowed to attach for $24 \mathrm{~h}$ before transfection. The cells were transfected with $200 \mathrm{ng}$ of either dat-1 cDNA (Jayanthi et al., 1998) or an empty vector (pcDNA3; Invitrogen, Carlsbad, CA) using TransITLT1 (Mirus, Madison, WI) as the transfection vehicle. At $48 \mathrm{~h}$ after transfection, the cells were fixed with $2 \mathrm{ml}$ of Prefer fixative (Anatech, Battle Creek, MI) for $15 \mathrm{~min}$. Cells were blocked for $1 \mathrm{~h}$ in TBS containing $2 \%$ Normal Goat Serum (NGS) (Jackson ImmunoResearch, West Grove, PA) and 0.2\% IGEPAL CA-630 (Sigma-Aldrich, St. Louis, MO). DAT-1 antiserum was preadsorbed with permeabilized dat-1(ok157) animals for $24 \mathrm{~h}$ at $4^{\circ} \mathrm{C}$. Transfected cells were incubated for $2 \mathrm{~h}$ at room temperature with precleared serum, diluted 1:100 in blocking agent. Finally, the cells were incubated for one hr at room temperature in a 1:5000 dilution of Goat anti-Rabbit CY3 labeled secondary antibody (Jackson ImmunoResearch).
C. elegans immunohistochemistry. Animals were fixed using 1\% formaldehyde in a modified Finney/Ruvkun fixation protocol (Finney and Ruvkun, 1990; Miller and Niemeyer, 1995). After fixation, animals were additionally permeabilized with a collagenase solution $(2 \mathrm{mg} / \mathrm{ml}$ collagenase type I, Sigma, $100 \mathrm{~mm}$ Tris pH 7.4, $1 \mathrm{~mm} \mathrm{CaCl}_{2}$ ) and shaken vigorously for $30 \mathrm{~min}$. Preabsorbed DAT-1 antiserum was used to stain wildtype and DAT-1 deficient nematodes at a concentration of 1:500 for $16 \mathrm{~h}$ at $4^{\circ} \mathrm{C}$. The $\mathrm{Cy} 3$ preabsorbed secondary $\mathrm{Ab}$ was used at a concentration of 1:1000. Indirect immunofluorescence images for both cell culture and nematode staining experiments were taken using an LSM510 confocal microscope (Vanderbilt University Medical Center Cell Imaging Core; supported by National Institutes of Health Grants CA68485 and DK20593).

For in vivo imaging of GFP fusion proteins, a series of $1.2 \mu \mathrm{m}$ image planes were obtained, creating a " $Z$ stack". $Z$ stacks were used to create three-dimensional (3D) reconstructions of images and have been noted in the figure legends. Single confocal image planes $(1.2 \mu \mathrm{m})$ containing either cell body or synaptic regions of selected strains were imaged and used to determine the peak GFP signal in different cellular compartments. Pixel density was calculated in MetaMorph (Molecular Devices, Sunnyvale, CA) by selecting an area of interest and obtaining a total fluorescence value. A minimum of 10 DA neurons per genotype was used for analysis.

\section{Creation of plasmids and transgenic animals}

Plasmids. All plasmids are described in supplemental Table 2 (available at www.jneurosci.org as supplemental material). $\mathrm{P}_{\text {dat }-1}$ :GFP::DAT-1 (Carvelli et al., 2004) and $\mathrm{P}_{\text {dat- } 1}:$ GFP (Nass et al., 2002) were described previously. To examine the functional necessity of the PDZ domain in DAT-1, we deleted the final $9 \mathrm{nt}$ from the distal $\mathrm{COOH}$ terminus of dat-1 creating a premature stop codon and ablating a PDZ motif $\left(\mathrm{IML}^{\star}\right)$ during translation. This fragment was cloned into the pRB491 plasmid described previously (Nass et al., 2002), replacing the full-lengthDAT-1 sequence, to create $\mathrm{P}_{\text {dat- }-1}$ :GFP::DAT-1( $\left.\Delta \mathrm{IML}\right)$. Similarly, to examine the consequences of removing a larger portion of the $\mathrm{COOH}$ terminal region, we deleted the final 25 amino acids from the DAT-1 COOH terminus by amplifying dat-1 cDNA without the terminal $75 \mathrm{nt}$ and introducing a premature stop codon instead. This fragment was cloned into pRB491 as above to create $\mathrm{P}_{d a t-1}$ :GFP::DAT-1 $(\Delta 25)$. To visualize the synaptic protein VMAT, we created $\mathrm{P}_{\text {dat }-1}$ :CAT-1::mRFP. mRFP was amplified from a pRSETv containing mRFP1 (gift from R. Tsien, UCSD) (Campbell et al., 2002) and the C. elegans VMAT (or CAT-1) was amplified from N2 genomic DNA. These sequences were cloned into pRB491, replacing dat-1 with $\mathrm{mRFP}$ and GFP with cat-1.

Transgenic animals. Stable transformants were created by coinjection of plasmid constructs with the marker plasmid pRF4[rol-6(su1006)] using standard methods (Mello et al., 1991). Unless otherwise noted, transgenic animals were obtained after coinjection of a final concentration of $15 \mathrm{ng} / \mu \mathrm{l}$ plasmid, $60 \mathrm{ng} / \mu \mathrm{l} \mathrm{pRF} 4[\mathrm{rol}-6$ (su1006)], and $50 \mathrm{ng} / \mu \mathrm{l}$ carrier DNA (pBluescript), into the dat-1 (ok157)III strain. L4 animals from lines containing extrachromosomal arrays that conveyed low penetrance were exposed to $50 \mu \mathrm{g} / \mathrm{ml}$ trimethyl Psoralen for array integration as previously reported (Clark and Chiu, 2003). All integrated lines were outcrossed 4 times to dat-1(ok157) animals unless otherwise noted.

\section{6-OHDA cell death assay}

The 6-OHDA toxicity assay was performed as described previously (Nass et al., 2002) with slight modifications. At $24 \mathrm{~h}$ after synchronization, L2/L3 animals were washed off of large NA22 plates and transferred to 1.5 $\mathrm{ml}$ of microcentrifuge tubes. An appropriate amount of $100 \mathrm{~mm}$ 6-OHDA in $20 \mathrm{~mm}$ ascorbic acid stock was added to the worm slurry making the final concentration either $50 \mathrm{~mm}$ 6-OHDA in $10 \mathrm{~mm}$ ascorbic acid (AA) or $25 \mathrm{~mm}$ 6-OHDA in $5 \mathrm{~mm}$ AA. Animals were then placed on a Nutator at room temperature for $1 \mathrm{~h}$. After treatment, animals were spread on a large $8 \mathrm{P} / \mathrm{NA} 22$ plate without removal of the 6-OHDA. After $72 \mathrm{~h}$ at $20^{\circ} \mathrm{C}$, animals were washed off plates and individual strains were placed onto separately prepared $2 \%$ agarose pads on slides for visualization. Strains were blinded for scoring and animals were scored on a 4 point scale with $4=$ no intact neurons and $0=$ all intact neurons. A total 
of 3 groups with 50 animals in each group made up the score for each strain. The total toxicity scored was determined as \% toxicity using the total number of neurons ablated for the group divided by 200 (total number of neurons in group).

\section{C. elegans assay for swimming induced paralysis}

All worms used for SWIP were grown on NGM plates spread with OP50 bacteria. For automated analysis, single L4 hermaphrodites were placed in $30 \mu \mathrm{l}$ of water in a single well of a Pyrex Spot Plate (Fisher catalog number 13-748B), and 10 min AVI movies of their swimming behavior were created and analyzed as described previously (Matthies et al., 2006). The resulting AVI movies were analyzed using a script written in MatLab 7.0.1 (The MathWorks), which discerns the position of the worm in every frame using motion detection and the selection of a pixel location that designates the worm centroid (described in detail by Matthies et al., 2006) (available on request). The calculated movement (in $\mathrm{Hz}$ ) for each window are placed in an array so that the frequency of the worm oscillation over time can be displayed. Average frequencies are determined for $6 \mathrm{~s}$ windows and plotted for each 10 min video segment. Population assays of 5-10 worms were analyzed as above, except that the AVI movies were scored for the number of animals moving at $10 \mathrm{~min}$. For reserpine treatment, worms from each line were synchronized by hypochlorite treatment and L1 larvae were grown on OP50 plates containing $0.6 \mathrm{~mm}$ reserpine. After $\sim 48 \mathrm{~h}$ of reserpine treatment, the population analysis was repeated on populations of L4 animals from each line.

\section{Results}

\section{Clearance of endogenous DA by DAT-1 is necessary for} thrashing behavior

Although multiple dat-1 alleles have been identified that both eliminate DA uptake in vitro and suppress the neurotoxic actions of exogenously applied 6-OHDA on DA neurons in vivo (Nass et al., 2005), an endogenous requirement for DAT-1 has not been demonstrated. Indeed, no overt locomotor phenotype is observed in dat-1 knock-out animals (dat-1(ok157)) when behavior is analyzed on standard culture substrates. Given that high concentrations of exogenous DA can paralyze animals in a DA receptor-dependent manner (Schafer and Kenyon, 1995; Chase et al., 2004), we reasoned that endogenous DA might exert inhibitory actions on the motor program if DA spillover to extrasynaptic sites (Chase et al., 2004) was permitted. To test this hypothesis, we placed wild-type and dat-1(ok157) animals in a liquid environment where they swim vigorously ("thrashing"), and analyzed their frequency of movement using an automated, computer-controlled method (Matthies et al., 2006). Whereas well fed, L4 stage, wild-type worms exhibit sustained thrashing behavior when placed in either water or M9 buffer for $>30 \mathrm{~min}$, dat-1 (ok157) worms become paralyzed within 6 min (Fig. 1A). Hereafter, we refer to this phenotype as "swimming-induced paralysis" or SWIP. SWIP is not evident in animals bearing loss-offunction alleles in tyrosine hydroxylase, the rate limiting step in DA biosynthesis [cat-2(e1112) (Lints and Emmons, 1999)) or the vesicular monoamine transporter (VMAT, cat-1(e1111) (Sulston et al., 1975; Duerr et al., 1999)] responsible for packaging DA for release (Fig. 1A). These findings indicate that endogenous DA normally inactivated by DAT-1 exerts an inhibitory action on motor circuits that support thrashing behavior. Exogenous serotonin (5-hydroxytryptamine, 5-HT), like exogenous DA, has been shown to paralyze worms (Schafer and Kenyon, 1995; Sawin et al., 2000; Chase et al., 2004). However, a loss-of-function allele in the serotonin transporter [SERT; mod-5(n3314) (Ranganathan et al., 2001)] fails to induce SWIP (Fig. 1A), demonstrating specificity and/or dominance of DA-dependent processes in this behavioral phenotype. To ensure that the SWIP phenotype in the dat-1 (ok157) line does not arise from an impact of the dele-
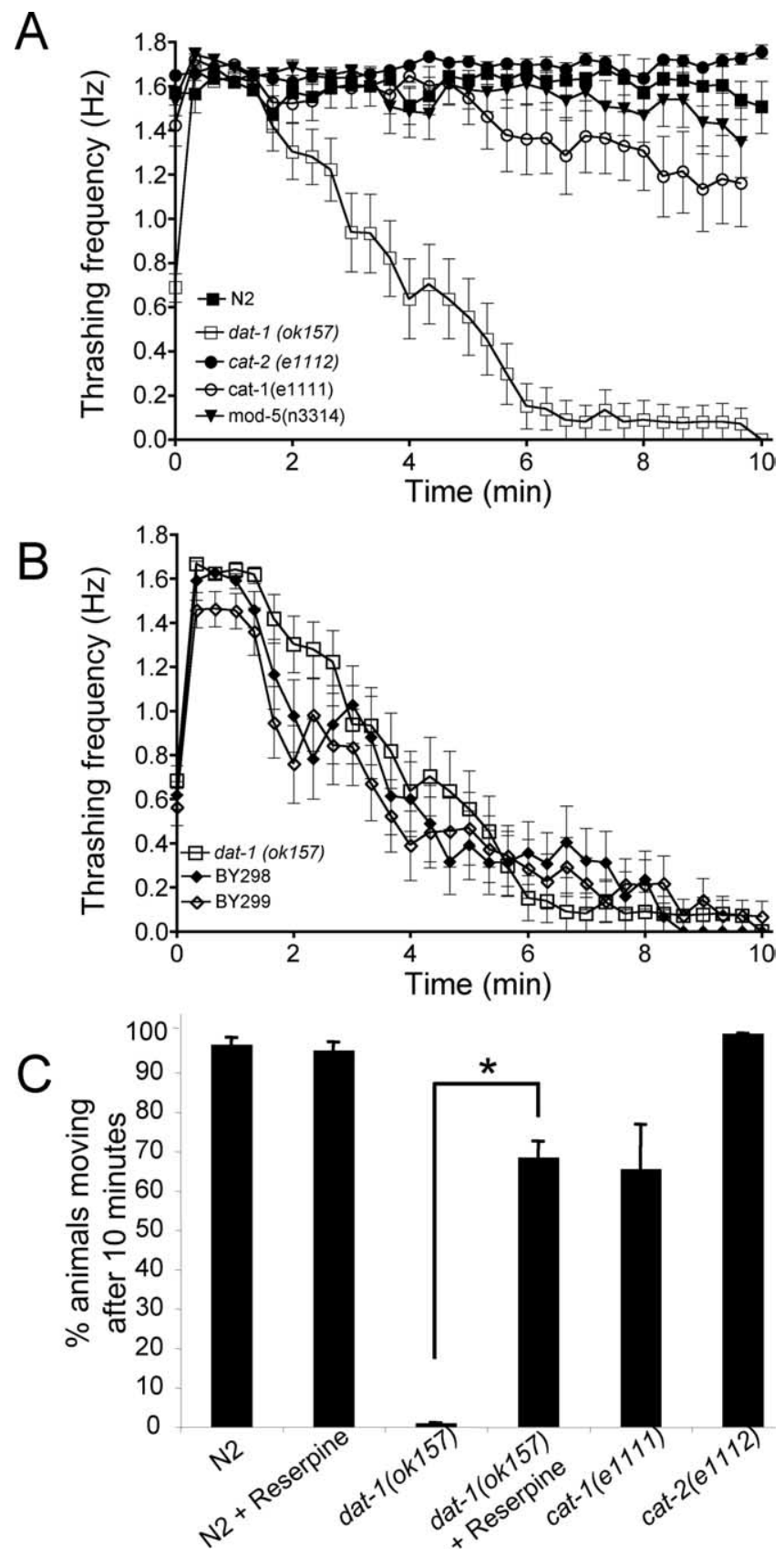

Figure 1. Clearance of synaptic DA is necessary for normal locomotor behavior. A, During the L4 stage of development, wild-type (N2) animals substantially increase their locomotor rate when placed in a liquid environment (water or $\mathrm{M} 9$ buffer) and swim at a steady rate for at least $30 \mathrm{~min}$. In contrast, dat-1 (ok157) mutants display swimming-induced paralysis (SWIP) within $10 \mathrm{~min}$. Worms lacking tyrosine hydroxylase (cat-2), SERT (mod-5), or VMAT (cat-1) do not exhibit SWIP, consistent with a reliance on released endogenous DA. B, Swimming behavior of L4 animals from the BY298 and BY299 strains, which contain the dat-1(vt2) and dat-1(vt3) mutant alleles, respectively. C, Inhibition of DA vesicular packaging rescues dat-1(ok157) paralysis. N2 and dat-1 (ok 157) worms were fed on $0.6 \mathrm{~mm}$ reserpine-treated plates for $48 \mathrm{~h}$ before analysis. For $\boldsymbol{A}$ and $\boldsymbol{B}$, single worms were assayed; for $\boldsymbol{C}$, populations of 5-10 worms were assayed simultaneously. Error bars represent SEM. ${ }^{*} p<0.001$, significant difference from dat-1(ok157). $p$ values were determined using unpaired Student's t tests. $n \geq 20$ per genotype for single worm analysis; $n \geq 40$ for population analysis.

tion on neighboring genes, we examined thrashing behavior in two additional dat- 1 alleles recovered in a forward genetic screen for suppression of 6-OHDA induced DA neuron degeneration (Nass et al., 2005). As shown in Figure 1 B, lines BY298 and 

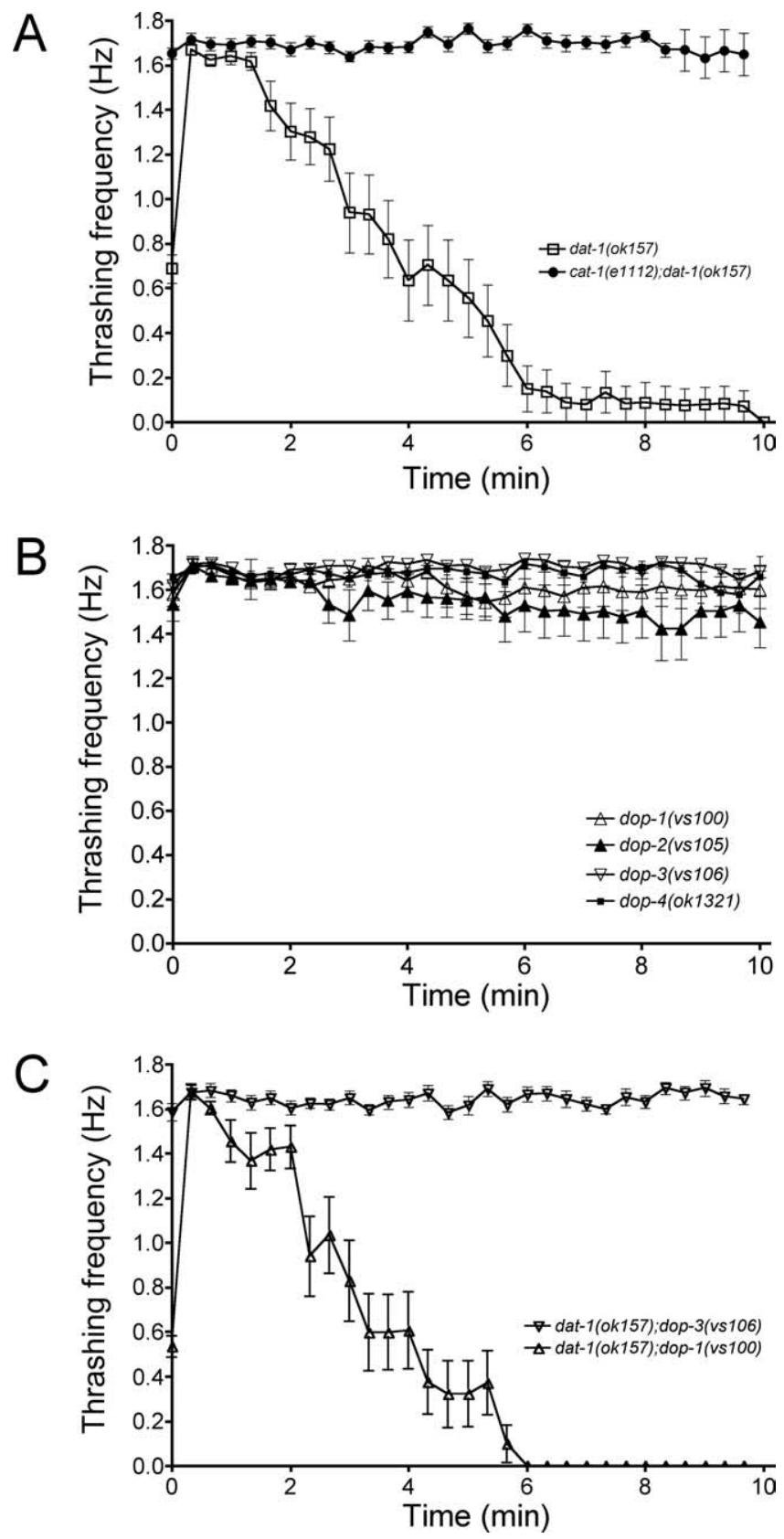

Figure 2. SWIP is mediated by the dopamine receptor DOP-3. A, A mutation in the tyrosine hydroxylase gene cat-2 suppresses SWIP in a dat-1(ok157) background, as expected if the observed paralysis is caused by released endogenous DA. dat-1(ok157) swimming behavior is replotted from Figure $1 A$ as a reference. $\boldsymbol{B}$, Swimming behavior in $L 4$ animals containing $m u-$ tations in each of the four identified dopamine receptor genes. All lines swam at a frequency comparable with wild-type (N2) animals. C, The dop-3(vs 106) mutation suppresses SWIP in dat-1(ok157) mutants, but the dop-1(vs100) mutation does not. Error bars represent SEM. $n \geq$ 20 per genotype.

BY299, which carry disabling point mutations in TM1 and 2 respectively (Nass et al., 2005), display time-dependent paralysis identical to that of the dat-1(ok157) line.

Generation of SWIP in multiple dat-1 mutant lines supports a requirement for functional DAT-1 protein in the maintenance of vigorous motor activity triggered by immersion in liquid. To confirm this hypothesis, we asked whether pharmacological or genetic suppression of DA production and signaling would eliminate SWIP in dat-1(ok157) mutants. The alkaloid reserpine is known to deplete vesicular stores of DA in vertebrates and nematodes through inhibition of VMAT activity (Erickson et al., 1992; Duerr et al., 1999). Wild-type animals raised on reserpinetreated plates displayed no change in thrashing behavior (Fig. $1 C)$, consistent with the absence of SWIP in cat-1 (e1111) animals, as noted above. In contrast, reserpine treatment significantly suppressed SWIP in the dat-1(ok157) line ( $p<0.05$, Student's $t$ test). Although we did not achieve full recovery with reserpine, we do not believe this is a pharmacological effect of the drug, because the level of recovery achieved with reserpine is equivalent to that seen in cat-1(e1111). However, because this level is reduced relative to the cat-2(e1112) allele, in which catecholamine synthesis (including DA) is significantly impaired (Sanyal et al., 2004), it is possible that the packaging of one or more other tyrosine-derived biogenic amines in addition to DA may also contribute to SWIP.

\section{The DA receptor $d o p-3$ is required for} swimming-induced paralysis

The studies described above support a role for the release of endogenous DA in the SWIP phenotype produced by DAT-1 loss of function. Indeed, cat-2(e1112); dat-1(ok157) double mutants, in which DAT-1 deficient animals are deprived of DA, show a complete rescue of SWIP (Fig. $2 \mathrm{~A}$ ). DA acts in mammals through multiple G-protein coupled receptors that have orthologs in $C$. elegans, DOP-1, 2, 3 and 4, respectively (for review, see McDonald et al., 2006). Otherwise wild-type animals bearing mutations in each of the DA receptor genes display normal thrashing behavior in our assays (Fig. $2 \mathrm{~B}$ ). Because DOP-1 and DOP-3 have been implicated in the paralytic actions of exogenous DA (Chase et al., 2004), we next examined transporter/receptor double mutant lines to specify the receptor involved in DAT-1 supported thrashing behavior. Whereas dat-1(ok157); dop-1(vs100) double mutants exhibit SWIP over the same time course as dat-1(ok157) animals, the dop-3(vs106) mutation completely suppresses SWIP in dat-1(ok157) (Fig. 2C). Coupled with the normal swimming behavior of the dop-3(vs106) line, these findings reveal the specific engagement of DOP-3 in antagonizing vigorous motor activity in a dat-1 (ok157) background.

\section{Cellular and subcellular localization of DAT-1 protein}

The powerful ability of DAT-1 to prevent the activation of DOP-3, thereby inhibiting the motor program, encouraged us to carefully examine the localization of DAT-1 in vivo. We approached this question in two ways: through the generation and utilization of DAT-1 specific antibodies, and through the DA neuron-specific expression of GFP::DAT-1 fusion proteins. Purified polyclonal antibodies were generated against a GST fusion peptide produced with the DAT-1 intracellular $\mathrm{COOH}$ terminus and examined for specificity using HEK293A cells transfected with dat-1 cDNA (Nass et al., 2005). Cells transfected with dat-1, but not empty vector, exhibited plasmalemmal staining with either of two antibodies (RB1565, RB1566) (Fig. $3 A, B$ ). Subsequently, preabsorbed RB1565 antiserum was used to identify sites of DAT-1 expression in wild-type animals with specificity validated in the dat-1(ok157) line (Fig. 3C, inset). A majority of wild-type animals displayed immunofluorescent labeling within the soma and processes of all DA head neurons, including the four cephalic (CEPs) neurons and the two anterior dierdic neurons (ADEs) (Fig. 3C). Significant immunofluorescence emanated from the $\mathrm{ADE}$ and $\mathrm{CEP}$ cell bodies (Fig. 3C, arrows), whereas the most intense labeling was localized to compartments typical of synaptic terminals innervating the nerve ring (Fig. 3C, 
asterisks). Immunofluorescence was much reduced along dendritic projections arising from the CEP cell bodies (Fig. 3C, arrowheads). Labeling of the two DA posterior dierdic neurons (PDEs) was rarely observed. The positions of all identified DAT-1 immunofluorescent cell bodies and termini are consistent with serial section electron micrograph images of DA neurons as well as with previously published $\mathrm{P}_{\text {dat- } 1}$ :GFP strains (Altun and Hall, 2005). No labeling above background was evident in the dat-1(ok157) deficiency strain (data not shown). Staining was most evident in L2-L3 and young adult animals and became progressively more difficult to detect as animals aged (data not shown).

To permit experiments examining genetic and structural determinants of DAT-1 localization, we fused GFP to the $\mathrm{NH}_{2}$ terminus of DAT-1 and expressed the fusion protein in the dat-1(ok157) strain using the $700 \mathrm{bp}$ promoter segment of the dat-1 gene $\left(\mathrm{P}_{\text {dat }-1}\right.$ :GFP::DAT-1) previously defined as suitable for DA neuron-specific gene expression (Nass et al., 2002). We used an $\mathrm{NH}_{2}$ GFP fusion in these studies because of increasing evidence that important information is present within the DAT COOH terminus for endocytic recycling (Loder and Melikian, 2003; Miranda et al., 2004) as well as plasma membrane targeting (Torres et al., 2001; Bjerggaard et al., 2004). GFP expression was evident in
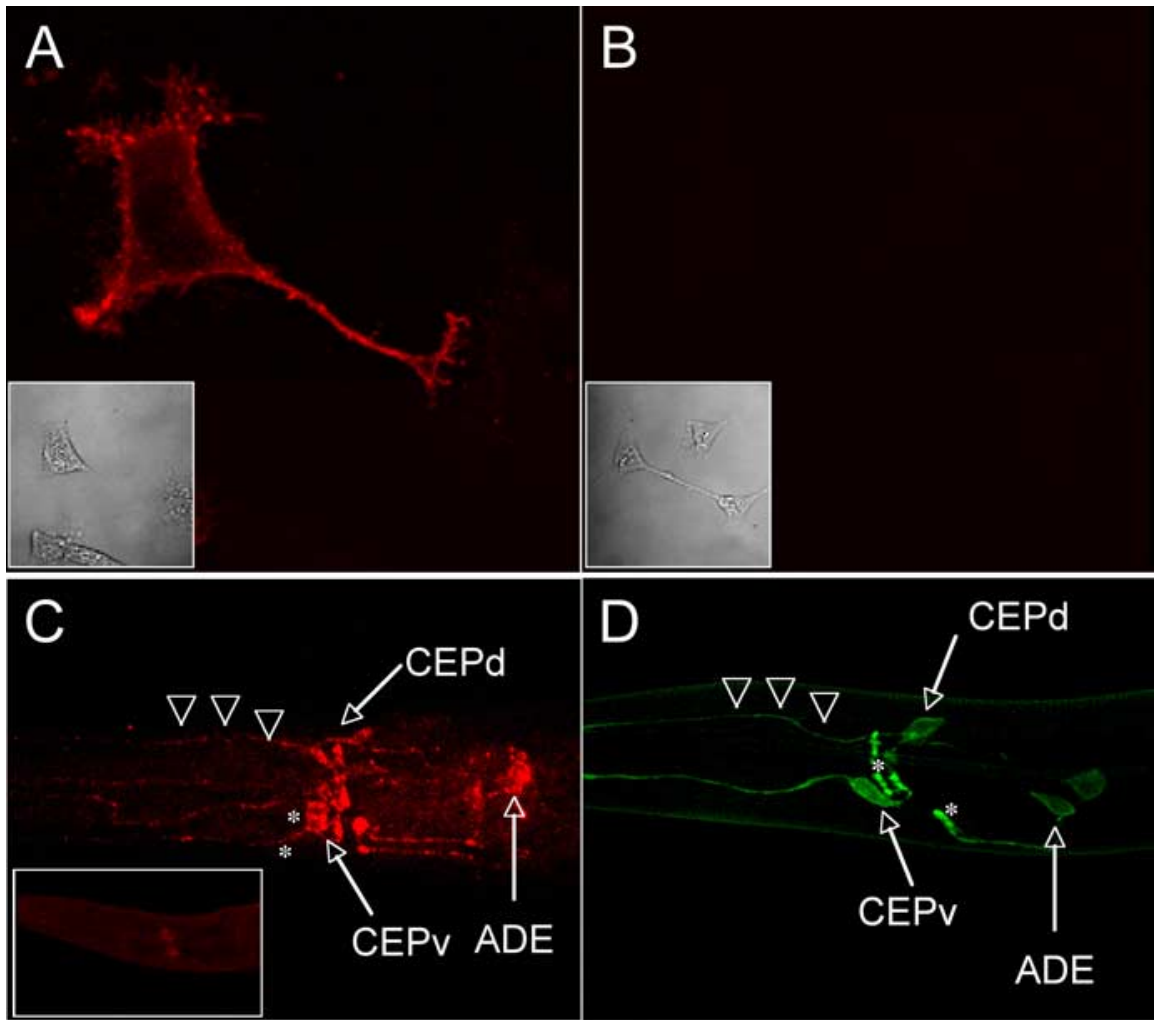

Figure 3. DAT-1 antibodies are specific for DAT-1 gene expression and recapitulate GFP::DAT-1 fusion localization in vivo. A, HEK cells transfected with a vector coding for DAT-1 show specific staining using the RB1565 antibody directed against the $\mathrm{COOH}$ terminus of DAT-1. B, Control cell lines transfected with empty vector. C, In situ staining of wild-type (N2) line revealing cell body (arrows), synaptic regions (asterisks), and dendritic (arrowheads) expression of DAT-1. Specific immunofluorescence was not detected in dat-1(ok157) animals (inset). D, Confocal imaging of GFP::DAT-1 fusion protein in vivo displaying expression in cell bodies (arrows), the nerve ring (asterisks), and dendrites (arrowheads). all of the DA neuron head groups (ADEs and CEPs) in each of the lines created, whereas expression in the posterior neurons (PDEs) was only rarely observed. Confocal imaging revealed GFP::DAT-1 expression in all analyzed regions of the 6 head DA neurons (Fig. 3D) with a pattern that mimicked the findings obtained with immunolocalization studies of endogenous DAT-1. The most intense fluorescence signals localized to discrete swellings along the CEP and ADE axonal projections and nerve terminals (Fig. 3D, asterisks). Expression of GFP::DAT-1 was evident in cell bodies, in which it was excluded from the nucleus, and appeared more intense along the plasma membrane. CEP dendrites displayed distinct immunofluorescence as well, although at visibly lower intensity than axonal elements (Fig. $3 D$, arrowheads). As observed in antibody studies, GFP::DAT-1 expression was highest in young animals, peaking between L2 and L3 and progressively decreasing in older animals (data not shown).

To verify the function of the GFP::DAT-1 fusion protein in vivo, we examined DA neuron sensitivity to the toxin 6-OHDA. This toxin requires DAT-1 mediated transport into C. elegans DA neurons to affect cell death (Nass et al., 2002, 2005). To monitor neural degeneration, soluble GFP was expressed in the DA neurons $\left(\mathrm{P}_{\text {dat }-1}\right.$ : GFP) of the dat-1 knock-out line (dat-1 (ok157) (Fig. $4 A$ ), wild-type worms (Fig. $4 B$ ), and the GFP::DAT-1 fusion line (Fig. 4C). All three strains were synchronized so that $\mathrm{L} 2$ animals could be tested for sensitivity to 6-OHDA (50 mM, $1 \mathrm{~h}$ ). As shown in Figure $4 D$, this protocol induces neural degeneration in $\sim 80 \%$ of wild-type animals expressing $\mathrm{P}_{\text {dat }-1}$ : GFP, which is evident by marked blebbing and loss of GFP fluorescence in dendritic pro- cesses (Fig. $4 B$, arrowheads). In contrast, only $\sim 10 \%$ of dat1(ok157) animals showed evidence of neural degeneration. Expression of GFP::DAT-1 in the dat-1(ok157) background, however, significantly recovered 6-OHDA sensitivity $(p<0.001$, one-way ANOVA), with nearly $70 \%$ of animals showing damage to CEP dendritic processes.

\section{DAT-1 and VMAT target to synapses in vivo via}

\section{distinct mechanisms}

Our analysis of DAT-1 immunoreactivity and GFP::DAT-1 distribution revealed conspicuous and specific accumulation in compartments consistent with presynaptic DA terminals within the nerve ring (Sulston et al., 1975). To better define these regions, a known synaptic protein, the vesicular monoamine transporter (VMAT or CAT-1) was tagged with mRFP and used for colocalization studies with GFP::DAT-1 in vivo. GFP::DAT-1 labeling, as noted above, was perinuclear in the soma and concentrated in presynaptic terminal-like structures in animals doubly transgenic for GFP::DAT-1 and VMAT::mRFP (Fig. 5B, arrow). GFP-DAT-1 labeling colocalized in these presynaptic structures with VMAT::mRFP fluorescence, consistent with their identity as synaptic boutons (Fig. $5 B, C$, arrows). In addition to synaptic labeling, VMAT::mRFP was also localized to an undefined punctate structure in the cell body (Fig. $5 B, C$, arrowhead). Expression of another synaptic vesicle fusion protein, synaptobrevin::mRFP, resulted in a similar labeling pattern in the cell soma of DA neurons (data not shown), indicating that this labeling may represent a bio-synthetic or trafficking compartment associated with synaptic vesicle proteins, although we cannot exclude the possibility 

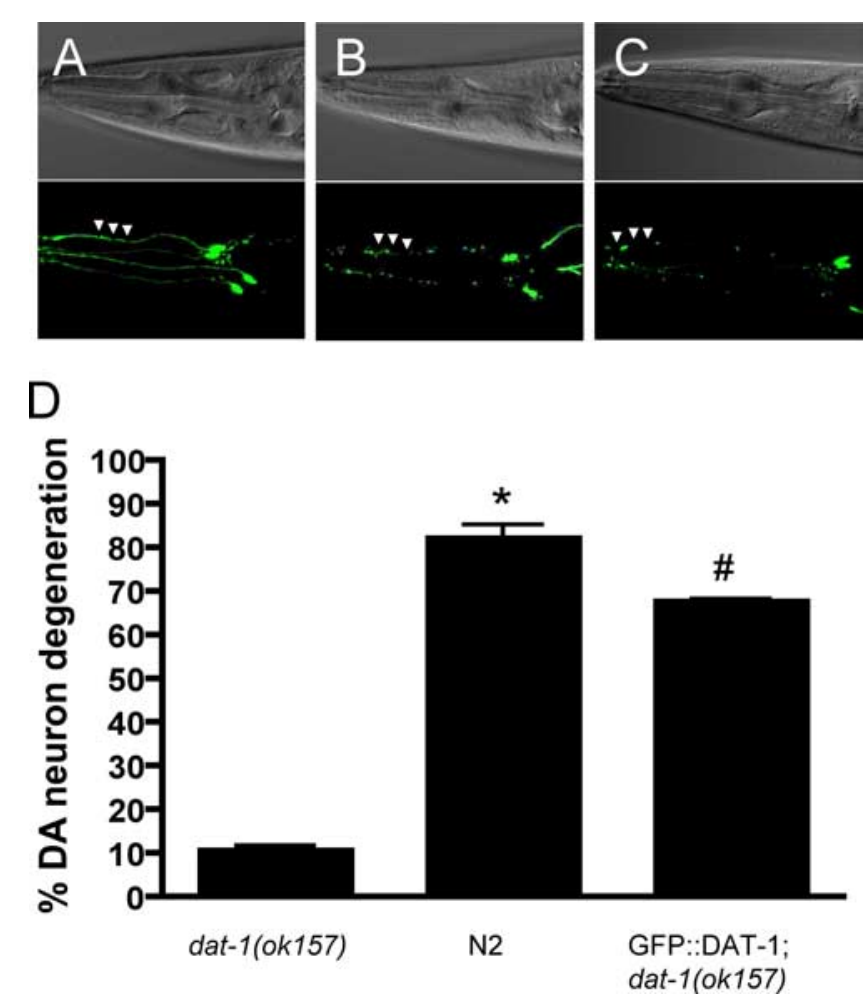

Figure 4. 6-OHDA toxicity in DA neurons in vivo. $\boldsymbol{A}-\boldsymbol{C}$, dat-1(ok157) does not display neuronal degeneration in the presence of 6-OHDA, whereas 6-0HDA exposure in wild-type $(\boldsymbol{B})$ and dat-1 (ok157) ( $C$ ) and lines expressing the $P_{\text {dat }-1}$ :GFP::DAT-1 transgene results in marked toxicity in DA neuronal projections ( $\boldsymbol{B}, \boldsymbol{C}$, arrowheads). $\boldsymbol{D}$, Quantification of DA neural degeneration reveals that transgenic rescue using GFP::DAT-1 restores 6-0HDA sensitivity to a level that is comparable, but still significantly reduced, with wild type. $p$ values were determined using a one-way ANOVA with Bonferroni's multiple comparison analysis. ${ }^{*} p<0.001$ versus GFP::DAT-1 and dat-1(ok157); ${ }^{*} p<0.001$ versus dat-1(ok157).

that transgene overexpression may contribute to this labeling. Less frequently, we observed VMAT::mRFP labeling in CEP dendrites. Interestingly, dendritic VMAT::mRFP labeling colocalized with GFP::DAT-1 (Fig. 5C, inset arrow), consistent with the presence of dendritic sites of DA release and uptake.

Previous studies have demonstrated that there are at least two mechanisms for the presynaptic enrichment of proteins in $C$. elegans: synaptic vesicle associated proteins are often delivered to synapses via the kinesin-like motor protein UNC-104 (Hall and Hedgecock, 1991), whereas other presynaptic proteins may be trafficked via dense-core vesicles (Ahmari et al., 2000; Zhai et al., 2001). Strains carrying hypomorphic mutations in unc-104 provide a very useful test to segregate these synaptic localization mechanisms. Included in the list of UNC-104 dependent proteins is the VMAT homolog CAT-1 (Duerr et al., 1999). To determine whether DAT-1 and CAT-1 share mechanisms of axonal transport in DA neurons, $\mathrm{P}_{\text {dat }-1}$ :GFP::DAT- 1 and $\mathrm{P}_{\text {dat }-1}$ :VMAT::mRFP lines were crossed to the hypomorphic unc-104(e1265) strain. As described above, VMAT::mRFP expression localized to puncta in the nerve ring in a wild-type background (Fig. $6 \mathrm{~A}$ ). In an unc104(e1265) background, however, mRFP signal is localized to the cell bodies of DA neurons (ADE and CEP neurons) (Fig. 6B, arrows). These results replicate findings using immunocytochemical approaches that localized CAT-1 to DA cell bodies in an unc-104(e1265) background (Duerr et al., 1999). The unc-104 hypomorph, however, had no effect on GFP::DAT-1 distribution (Fig. 6C,D). Quantitation of the relative subcellular localization of GFP::DAT-1 confirmed that the unc-104(e1265) background has no effect on synaptic accumulation (see below). Consistent with these findings, 6-OHDA sensitivity of unc-104(e1265) animals expressing $\mathrm{P}_{\text {dat- } 1}$ :GFP showed comparable toxicity with wild-type animals expressing $\mathrm{P}_{\text {dat- } 1}$ :GFP (Fig. 7). To ensure that these negative findings were not an artifact of the GFP tag, the unc-104(e1265) strain was permeabilized and indirect immunofluorescence assays were performed to examine native DAT-1 localization. As observed with GFP::DAT-1 studies, no impact on native DAT-1 distribution was observed (data not shown). These data are the first, to our knowledge, that reveal that distinct pathways support the synaptic localization of DAT and VMAT proteins and encouraged us to explore further the mechanisms supporting in vivo DAT-1 trafficking in this model.

Quantitative analysis of GFP::DAT-1 subcellular localization Our ability to directly visualize the localization of GFP::DAT-1 in multiple neuronal compartments affords a quantitative assessment of neurotransmitter transporter compartmentation in vivo. For this analysis, confocal image planes were captured from the DA neurons of GFP::DAT-1 animals. Relative pixel intensity was then determined as described in Materials and Methods for three distinct neuronal areas: synaptic regions (Fig. $8 A$ ), cell bodies (Fig. $8 B$ ), and dendritic processes (data not shown). A representative scan from a single transgenic animal reveals a Gaussian distribution of GFP::DAT-1 signal overlying DA synapses (Fig. $8 C$ ), whereas a scan through the cell body reveals a bimodal distribution with peaks at or near the plasma membrane indicative of perinuclear localization (Fig. $8 D$ ). After Z-scans to identify signals of greatest intensity, values from multiple animals were then collected and organized by compartment. Synaptic regions consistently displayed the greatest peak fluorescence intensity [118.8 \pm 3.9 arbitrary fluorescence units (AFU)], whereas cell body fluorescence was $\sim 40 \%$ lower $(73.5 \pm 4.5$ AFU). Fluorescence in dendrites was lower still $(38.0 \pm 8.5$ AFUs $), \sim 70 \%$ reduced from synaptic regions (Fig. $8 E, G$ ). To determine whether this pattern is shared with other proteins nonspecifically, we compared the expression of GFP::DAT-1 with that of a cytosolic fluorophore [pTimer (Terskikh et al., 2000)]. In contrast to the transporter fusion, the cytosolic reporter showed only limited signal overlying synapses, displaying instead a predominant accumulation of fluorescent signal in the cell body (Fig. $8 \mathrm{~F}, \mathrm{H}$ ). These data document a non-uniform distribution of GFP::DAT-1 within DA neurons, with significant enrichment at synaptic sites, presumably to achieve efficient reuptake of released DA.

\section{COOH terminal DAT-1 sequences participate in synaptic localization}

Our ability to quantitate the relative distribution of the GFP::DAT-1 fusion among neuronal compartments and development of the SWIP assay provides a unique opportunity both to examine the contribution of specific domains within DAT-1 to transporter localization and the impact of loss of synaptic transporter targeting to endogenous DA signaling. DAT-1 bears a canonical type II PDZ domain recognition sequence (IML) at its $\mathrm{COOH}$ terminus (Kornau et al., 1997). Although this motif has been implicated in synaptic localization in neuronal cultures mediated by direct interactions with PICK-1 (Torres et al., 2001; Bjerggaard et al., 2004; Farhan et al., 2004), the importance of this mechanism in vivo is unknown. We therefore expressed a GFP::DAT-1 construct lacking the PDZ interaction sequence $\left(\mathrm{P}_{\text {dat }-1}\right.$ :GFP::DAT-1( $\left.\left.\Delta \mathrm{IML}\right)\right)$ in the DA neurons of dat-1(ok157). Low concentrations of DNA $(15 \mathrm{ng} / \mu \mathrm{l})$ typically used to create 
transgenic lines produced strains that displayed no detectible GFP signal (data not shown). DNA was therefore injected at increasing concentrations (30,60, and, $90 \mathrm{ng}$ / $\mu \mathrm{l})$ until a stable transgenic line was obtained that displayed detectable GFP signal in all DA head neurons (at $90 \mathrm{ng} / \mu \mathrm{l}$ ). We assessed these animals for 6-OHDA sensitivity as previously described and found significant rescue of toxin sensitivity (Fig. 7).

To attempt more quantitative analyses of how protein expression from transgenes relates to transporter functional expression, we quantified DA uptake using embryonic primary cultures (Carvelli et al.,
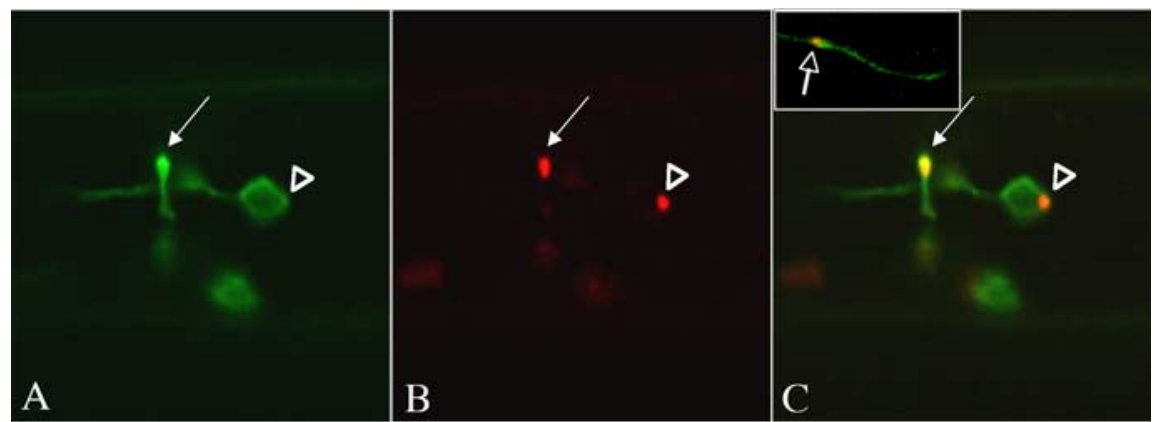

Figure 5. GFP::DAT-1 localizes with VMAT::mRFP in terminals in vivo. A-C Single confocal image planes including both the CEP cell body and terminals reveal that GFP::DAT-1 ( $\boldsymbol{A})$ colocalizes with VMAT:: mRFP $(\boldsymbol{B})$ at synaptic regions (arrows). This colocalization of GFP::DAT-1 in the terminals is not noted in regions of the cell body ( $\boldsymbol{A}-\boldsymbol{C}$, arrowheads). Colocalization of GFP::DAT-1 and VMAT::mRFP was also detected in discrete swellings in dendritic projections ( $\boldsymbol{C}$, inset arrow). 2004) from both high and low expressing GFP::DAT-1 transgenic lines (BY320 and BY312 respectively), as well as from the $\mathrm{P}_{\text {dat- } 1}$ :GFP::DAT-1( $\left.\Delta \mathrm{IML}\right)$ line. DA uptake arising from expression of the $\Delta \mathrm{IML}$ line $(0.065 \pm 0.012$ $\mathrm{fmol} \cdot \mathrm{min}^{-1} \cdot \mathrm{mg}^{-1}$ protein) was intermediate to the two fulllength GFP::DAT-1 fusion lines (BY320: $0.099 \pm 0.013 \mathrm{fmol} /$ $\mathrm{min} / \mathrm{mg}$ protein; BY312: $0.035 \pm 0.004 \mathrm{fmol} \cdot \mathrm{min}^{-1} \cdot \mathrm{mg}^{-1}$ protein). When DA uptake in cultures is normalized either by in vivo GFP fluorescence or by DAT-1 levels in worms as assessed by Western blots, no significant differences were evident between the three lines (data not shown). These data indicate that although the $\Delta \mathrm{IML}$ construct is inefficiently expressed in vivo, the PDZ recognition sequence is not necessary for proper cell surface targeting. To ensure that contributions from a contaminating wild-type dat-1 allele did not affect our interpretation of this data, genotyping was performed on the lines used for the latter experiments and no wildtype dat-1 contamination was found in any of the GFP::DAT-1 translational fusion lines (data not shown).

Next we sought to determine how modification of the DAT-1 $\mathrm{COOH}$ terminus effects synaptic localization in vivo. The synaptic enrichment of full-lengthdat-1 (Fig. $9 A, B$ ) is maintained in an unc-104(e1265) background (Fig. 9C,D), consistent with results noted above. Additionally, the subcellular localization pattern achieved with GFP::DAT-1( $\triangle \mathrm{IML})$ was indistinguishable from wild-type GFP::DAT-1 (Fig. 9E,F). Although fusion of GFP sequences to human DAT ablates PICK-1 binding and surface expression (Bjerggaard et al., 2004; Madsen et al., 2005), a $\mathrm{COOH}$ terminal GFP fusion to full-length DAT-1 (DAT-1:GFP) (Fig. $9 F, G)$ failed to impact the synaptic enrichment of the transporter. These findings reveal that the PDZ motif at the $\mathrm{COOH}$ terminus of the C. elegans DAT-1 plays little role in synaptic localization.

In addition to the PDZ domain, several other residues in the $\mathrm{COOH}$ terminus of DATs are also known to be involved in transport from the ER to the plasma membrane or in endocytic recycling (Loder and Melikian, 2003; Miranda et al., 2004). To examine whether the disruption of a larger portion of the $\mathrm{COOH}$ terminus could affect synaptic localization of DAT-1, we examined the expression of GFP::DAT-1 fusion that lacks the final $\mathrm{COOH}$ terminal 25 amino acids $\left[\mathrm{P}_{\text {dat }-1}\right.$ :GFP::DAT-1 $\left.(\Delta 25)\right]$. As expected from the deletion of the IML sequence, expression of this construct required significantly higher DNA concentrations $(90 \mathrm{ng} / \mu \mathrm{l})$. In contrast to more limited disruption of the DAT-1 $\mathrm{COOH}$ terminus, this deletion completely eliminated synaptic enrichment (Fig. 9I,J).
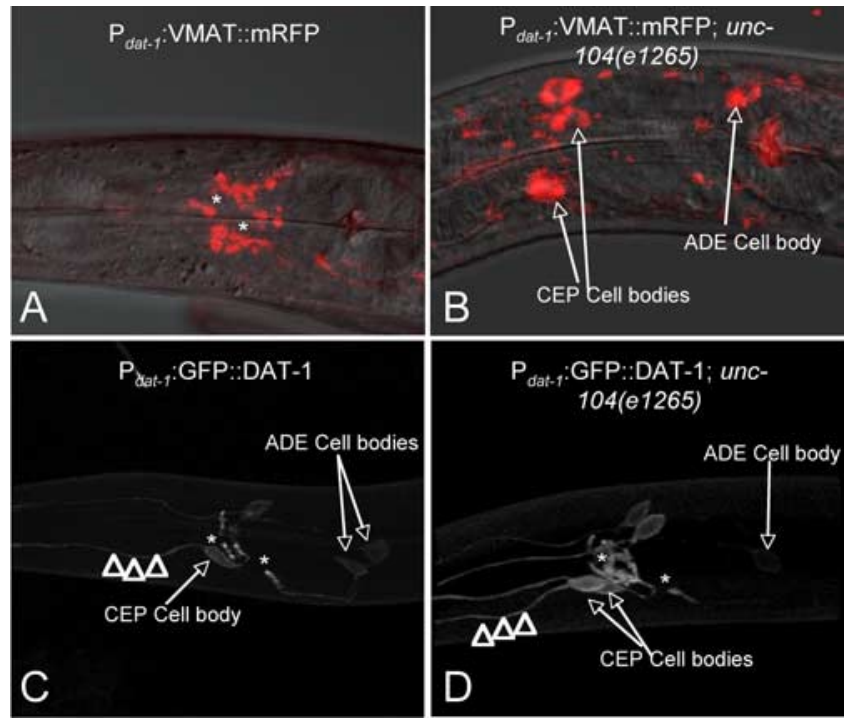

Figure 6. VMAT::mRFP trafficking to the synapse depends on a functional UNC-104 kinesin motor protein in vivo, but GFP::DAT-1 trafficking does not. Confocal image stacks were collected in both the differential interference contrast (DIC) and RFP channels and used to compare location of mRFP signal with anatomic localization. $A$, A single DIC image plane of a wild-type worm expressing an integrated VMAT::mRFP reveals that the majority of the RFP signal seen in the $3 D$ reconstruction emanates from the nerve ring. $\boldsymbol{B}$, Analysis of VMAT::mRFP in an unc104(e1265) background reveals that the VMAT::mRFP localization to the nerve ring requires a functional UNC-104 protein. Without UNC-104, VMAT::mRFP is retained in the DA neuron cell bodies (ADEs and CEPs, arrows). C, GFP:::DAT-1 in dat-1(0k157) background (BY312) is observed in the cell bodies (ADE and CEP) and elaborated into both the dendrites (arrowheads) and synaptic regions of the nerve ring (asterisk). D, GFP::DAT-1 in the mutant unc-104(e1265) background has no effect on GFP::DAT-1 localization with GFP signal remaining in both dendrites and nerve ring structures (arrowheads and arrows).

\section{COOH terminal DAT-1 sequences support DAT-1 function in vivo}

Localization of GFP fluorescence gives no information as to whether DA clearance capacity in vivo is retained or lost. For example, synaptic enrichment of GFP::DAT-1( $\Delta \mathrm{IML})$ might occur, but preclude functional expression of transporters at the cell surface. We therefore pursued an analysis of the behavioral impact of DAT-1 COOH terminal mutations. Consistent with fluorescence localization studies and recovery of 6-OHDA sensitivity, the GFP::DAT-1( $\Delta \mathrm{IML})$ construct appears to provide significant DA clearance in vivo as estimated by significant rescue of SWIP arising from genetic ablation of dat-1 (Fig. 10). In contrast, the lack of synaptic expression of GFP::DAT-1 $(\Delta 25)$ was paralleled by a lack of suppression of SWIP. 


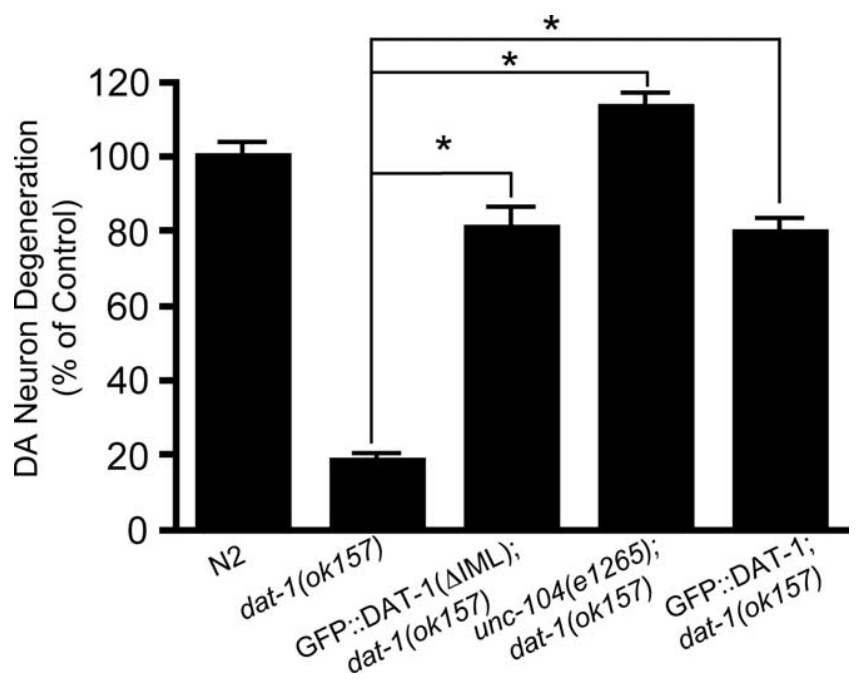

Figure 7. Both unc-104 and $\triangle I M L$ mutant lines rescue 6-OHDA toxicity to wild-type and GFP::DAT-1 levels. N2 strains carrying GFP in all DA neurons were used as controls to determine 6-OHDA toxicity. All data were normalized to the average toxicity recorded for the wild-type (N2) line (100\%) to get a percentage of control value. The unc-104(e1265) line displayed toxicity that was consistent with the wild-type line. The GFP::DAT-1( $\Delta \mathrm{IML})$ line displayed toxicity that was slightly and significantly reduced but indistinguishable from the GFP::DAT-1 fulllength construct. Error bars represent SEM. ${ }^{*} p<0.001$, significant difference versus dat$1(0 k 157)$. $p$ values were determined using a one-way ANOVA with Bonferroni's multiple comparison analysis.

\section{Discussion}

DA signaling in C. elegans has been implicated in the modulatory control of egg-laying, defecation, motor activity, response to food, and habituation to touch (for review, see McDonald et al., 2006). Worms exposed to high levels of DA (e.g., $10 \mathrm{~mm}$ ) exhibit discernible behavioral phenotypes. For example, locomotor paralysis occurs when worms are cultured on exogenous DA (Schafer and Kenyon, 1995; Sawin et al., 2000; Chase et al., 2004), a phenotype that is dependent on both the D1-like DA receptor DOP-1 and the D2-like receptor DOP-3 (Chase et al., 2004). Because in vitro approaches require high concentrations of exogenous DA to penetrate the nematode cuticle, they likely overwhelm normal DA clearance mechanisms (such as that provided by DAT-1), and allow DA to act extrasynaptically. Interestingly, recent studies demonstrate that extrasynaptic DA signaling may play a significant role in the nematode under normal culture conditions as well: although the eight DA neurons containing DAT-1 synapse onto 41 neuron subtypes in the nematode, only one of these neurons is known to express DOP-1 and DOP-3 (White et al., 1986; Chase et al., 2004). These studies indicate that there is little overlap between the expression patterns of DAT-1 and DOP-1/DOP-3 and suggest that DA must diffuse away from its site of release to mediate signaling via DOP-1 and DOP-3. As a result, uncertainties remain as to the functional contribution of DAT-1 in vivo. In this report, we have identified a novel behavioral phenotype, swimming-induced paralysis (SWIP), that is dependent on endogenous DA release, synaptic inactivation by DAT-1, and signaling via the DA receptor DOP-3. Elevated extracellular DA is a well known consequence of DAT knock-out mice (Giros et al., 1996) and in DAT-1 deficient worms, we suspect the DOP-3 pathway is now engaged via the spillover of extrasynaptic DA, triggering SWIP. Similarly, DAT-1 reversal triggered by the psychostimulant amphetamine rapidly induces SWIP in wild-type worms (Lucia Carvelli, unpublished results). If instead SWIP derives from desensitization of DOP-3 by extra-
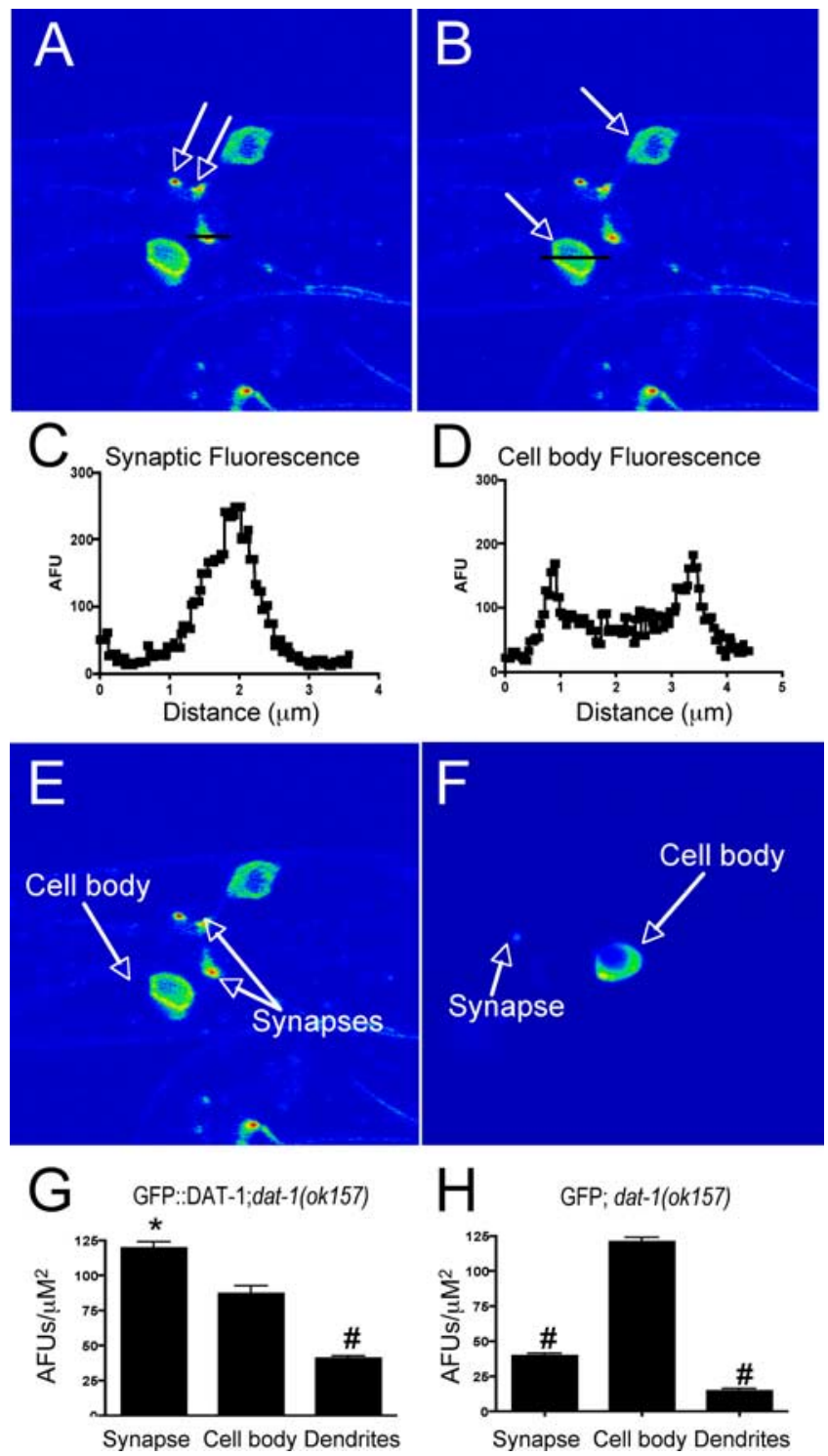

Figure 8. GFP::DAT-1 accumulates at the synapse in vivo. Single confocal image planes are used to determine relative fluorescence in both the cell body and nerve terminals in vivo. $\boldsymbol{A}$, Pseudocolored image of GFP::DAT-1; dat-1 (ok157) shows synaptic accumulation at the synapse (arrows). $\boldsymbol{B}$, The same GFP::DAT-1; dat-1(ok157) image highlighting cell body GFP::DAT-1 accumulation in the cell bodies (arrows). $C, D, A$ line scan over the synapse (line, $A$ ) or cell body (line, $\boldsymbol{B}$ ) reveals the punctate nature of the synapse $(\boldsymbol{C})$ and the plasma membrane association (either as vesicles or directly inserted) of DAT-1 in the cell body (D). Images were obtained so that the highest intensity pixel was just below saturation of the detector (typically the synapse), and GFP density was measured by circling the synapse or cell body in MetaMorph. $\boldsymbol{E}-\boldsymbol{H}$, Values obtained from a population of images $(n=20)$ reveal that GFP::DAT-1 accumulates preferentially at the synapse $(\boldsymbol{E}, \boldsymbol{G})$ compared with a cytosolic fluorophore, pTIMER, which is retained in the cell body $(\boldsymbol{F}, \boldsymbol{H})$. Error bars represent SEM. ${ }^{*} p<0.001$, significant difference increase in GFP density versus cell body. ${ }^{\#} p<0.001$, significant decrease in GFP density versus cell body. $p$ values were determined using a one-way ANOVA with Bonferroni's multiple comparison analysis.

synaptic DA, we would have expected a genetic loss of DOP-3 to also generate SWIP. This phenotype would appear easily amenable to forward and reverse genetic studies that seek to elaborate presynaptic determinants of DAT-1 expression or postsynaptic DOP-3-mediated DA signaling.

The critical role we identified for inactivation of synaptic DA via DAT-1 for prevention of DA spillover and suppression of the motor program prompted us to examine localization of DAT-1 in 

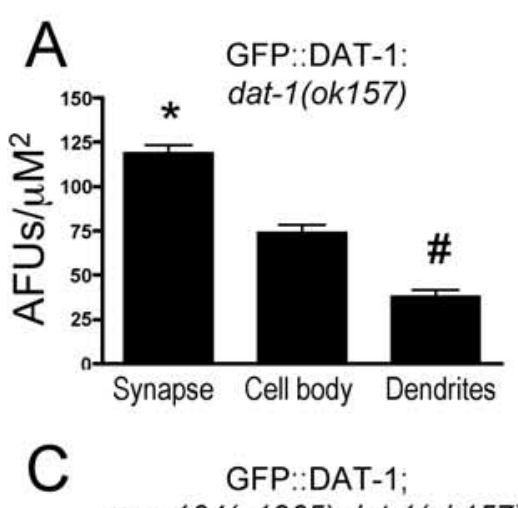

unc-104(e1265);dat-1(ok157)
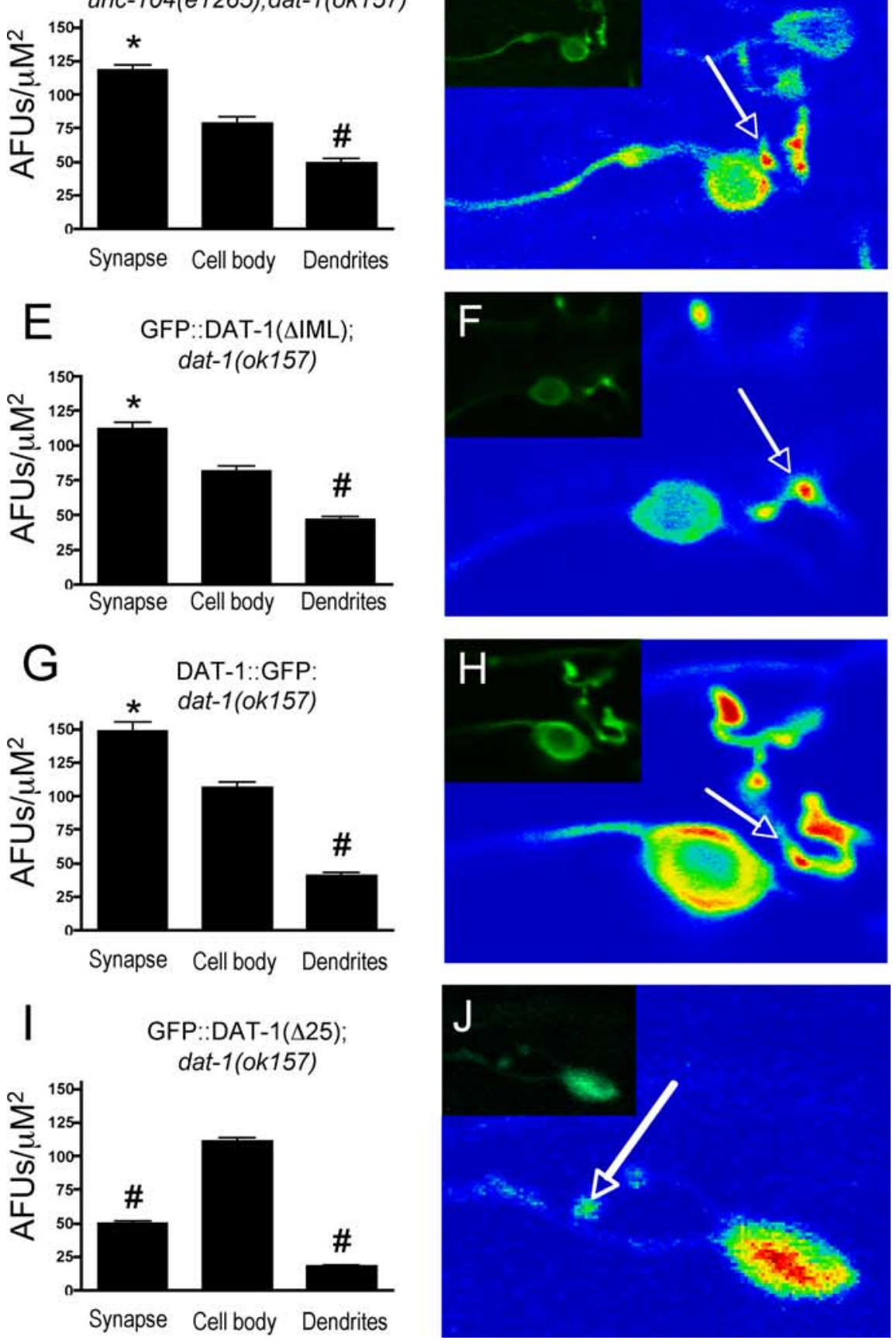

Figure 9. $\Delta \mathrm{IML}$ and unc-104 mutations have no effect on synaptic accumulation in vivo. GFP density was measured for the cell body, synapse, and dendrite and compared for the different lines. $\boldsymbol{A}, \boldsymbol{B}$, As shown in Figure 6, GFP density measures in GFP::DAT-1 reveal synaptic accumulation in both the GFP ( $\boldsymbol{B}$, inset) and pseudocolor ( $\boldsymbol{B}$, arrow) images. $\boldsymbol{C}, \boldsymbol{D}$, IML truncation does not affect synaptic accumulation. Representative GFP and pseudocolor image are shown for the $\Delta I M L$ line. $E, F$, DAT-1:GFP protein accu- vivo. Using DAT-1 specific antibodies and GFP::DAT-1 fusion proteins, we localized the transporter to perinuclear regions of the cell body, to a minor degree in dendrites, and at significant concentrations in synaptic regions. This data are reminiscent of antibody studies in both rat midbrain and human neurons that show DAT in cell bodies, dendrites, and at perisynaptic regions in nerve terminals (Lorang et al., 1993; Nirenberg et al., 1997a,b; Ciliax et al., 1999). The $\mathrm{NH}_{2}$ terminal GFP::DAT-1 fusion protein allowed for a quantitative assessment of DAT-1 steady-state localization. Overall expression levels differed in the three sets of DA neurons: the greatest expression was observed in the four CEP neurons, followed by a mild reduction of expression in the two ADE neurons, and significant reduction in the two PDE neurons, implying that there may be different regulatory elements in these cells. Low DAT-1 density in PDE neurons may account for the reduced susceptibility to 6-OHDA toxicity that has been reported for these neurons previously (Nass et al., 2002) and may point to the physiological source for DA released to act on extrasynaptic DA receptors in suppression of motor activity. The loss of DAT-1 in the dat-1 KO line may thus add a novel source of extrasynaptic DA from CEP and ADE neurons, normally constrained for synaptic actions by the transporter. A differential expression of DAT proteins is also evident in mammalian DA neurons in which DATs are expressed highly in substantia nigra neurons and at lower levels in ventral tegmental neurons with minimal expression in DA neurons of the arcuate nucleus that release DA into the portal circulation (Hoffman et al., 1998).

SWIP is only prominent in young animals and is much less evident in nematodes beyond the L4 stage of development. We do not understand the mechanisms implicated by age-dependent locomotor $\longleftarrow$

mulates at the synapse similarly to GFP::DAT-1, but there is a significant $\left.{ }^{* *} p<0.01\right)$ increase in fluorescent density in both the cell body and the synapse. This increase can be seen in both the GFP $(\boldsymbol{F}$, insert) and pseudocolor image $(\boldsymbol{F}$, arrow). $\boldsymbol{G}, \boldsymbol{H}$, When the GFP::DAT-1 lines were crossed to unc-104(e1265) strains, no change in the overall distribution of GFP accumulation was noted. I, J, $\Delta 25$ truncation clearly affects synaptic accumulation. Intracellular retention and a lack of synaptic accumulation are evident in both GFP and pseudocolor images. Error bars represent SEM. ${ }^{*} p<0.001$, significant difference increase in GFP density versus cell body; ${ }^{*} p<0.001$, significant decrease in GFP density versus cell body. $p$ values were determined using a one-way ANOVA with Bonferroni's multiple comparison analysis. 


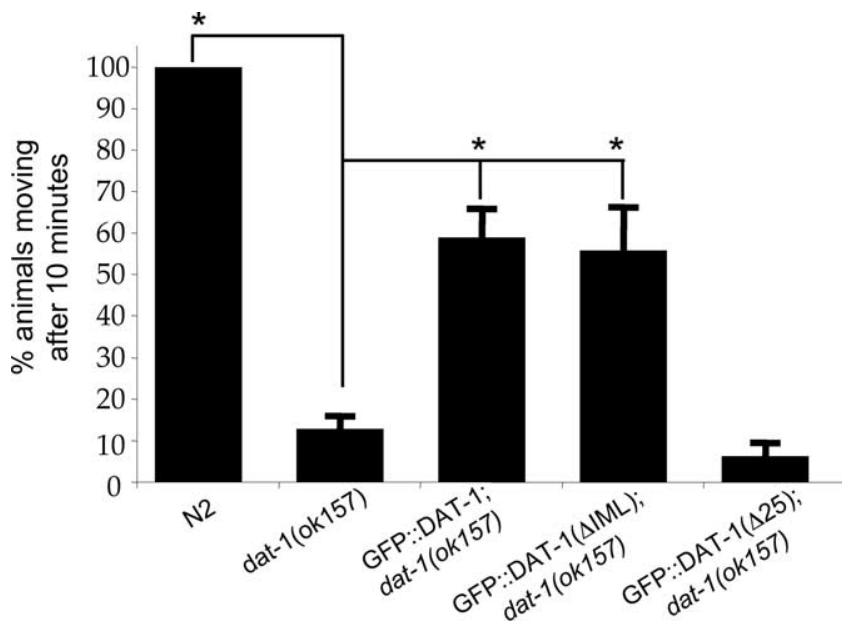

Figure 10. The GFP::DAT-1 transgene rescues SWIP in dat-1(ok157) worms. Swimming behavior of $L 4$ worms expressing the dominant marker rol-6(su1006) was examined. Locomotor analysis was performed as above, except that populations of 5-10 worms were assayed simultaneously. N2 worms expressing rol-6(su1006) do not swim in a coordinated manor but continue to move in liquid for at least $10 \mathrm{~min}$, whereas dat-1(0k157) worms expressing rol6(su1006) paralyze at a rate similar to dat-1(ok157) alone. Both DAT-1:GFP and DAT-1: $\operatorname{GFP}(\Delta I M L)$ rescue SWIP, but DAT-1:GFP $(\Delta 25)$ does not. Error bars represent SEM. ${ }^{*} p<0.001$, significant difference from dat-1(ok157). $p$ values were determined using a one-way ANOVA with Bonferroni's multiple comparison analysis; $n \geq 40$ for each genotype.

changes, although it is interesting that this observation parallels the reduction in DAT-1 antibody staining and GFP::DAT-1 fluorescence observed over the course of an animal's lifetime. DAT-1 immunoreactivity and GFP::DAT-1 expression peaked between the L2 and L3 larval stages and decreased in aging animals (data not shown). As we see the same pattern with endogenous and transgenic DAT expression, the promoter fragment we used for DA neuron expression may harbor elements that support age-dependent suppression of transcription. Age-related reductions in DAT mRNA levels have been reported in the substantia nigra of humans (Bannon et al., 1992) and are suggested to support the well known age-dependent risk for Parkinson's disease. Forward genetic approaches to uncover determinants of age-dependent reductions in DAT expression, by restitution of SWIP in aged nematodes for example, is an additional opportunity suggested by our studies.

By using confocal imaging of DA neuron projections in living animals, we established that GFP::DAT-1 protein is enriched in synaptic compartments. All synaptic vesicle proteins tested to date in C. elegans require the functional kinesin motor protein UNC-104 (Hall and Hedgecock, 1991; Nonet et al., 1993, 1998; Duerr et al., 1999). The accumulation of GFP::DAT-1 at the synapse is not therefore a consequence of export from the cell body on synaptic vesicle precursors. Use of the constitutive secretory pathway may thus be engaged, coupled with synaptic recycling to sustain high levels at the synapse. Such a mechanism has recently been suggested for the GABA transporter GAT-1 in which nonSNARE mediated exocytosis and trafficking has been argued to be mediated by exocyst proteins (Farhan et al., 2004).

The regulation of DAT proteins is tightly controlled by multiple interacting proteins as well as kinase/phosphatase-linked pathways (Melikian, 2004; Foster et al., 2006). Sequences in the transporter's $\mathrm{COOH}$ terminus have been implicated in the trafficking of DAT through biosynthetic compartments (Bjerggaard et al., 2004) and to the cell surface (Torres et al., 2001; Carneiro et al., 2002), as well as in endocytic trafficking (Miranda et al., 2004;
Holton et al., 2005). The role of the conserved type II PDZ recognition sequence located at the distal COOH terminus of DAT has gained specific attention for its potential role in synaptic targeting. Torres et al. reported an interaction between hDAT and the protein kinase $\mathrm{C}$ interacting protein PICK1 that was dependant on PDZ recognition sequence of hDAT (Torres et al., 2001). Furthermore, Bjerggaard et al. found that PDZ truncation of hDAT resulted in to intracellular retention and an overall reduction in hDAT expression, leading them to conclude that the PDZ recognition sequence is not important for cell surface targeting, but may be important for protein stability and/or expression (Bjerggaard et al., 2004).

In our study, the deletion of the PDZ recognition sequence ( $\Delta \mathrm{IML}$ ) had no effect on 6-OHDA toxicity, DA uptake, or synaptic targeting. Furthermore, we previously reported that the $\mathrm{COOH}$ terminal GFP fusion rescues 6-OHDA sensitivity in vivo (Nass et al., 2002), and cultured neurons from this line demonstrate DA uptake capacity consistent with total expression levels. We are not the first to report a lack of effect from ablation of a PDZ recognition sequence in vivo. Despite evidence that disruption of PDZ binding domain interactions block synaptic delivery of AMPA receptors and LTP induction in vitro (Hayashi et al., 2000), in vivo expression of a PDZ-ablated GluR1 receptor, which replaced the endogenous GluR1 gene, failed to disrupt either synaptic localization or LTP induction (Kim et al., 2005). Likewise, complete ablation of this conserved interaction domain would indicate that it is not used for DAT-1 localization in $C$. elegans. Disruption of a larger portion of the $\mathrm{COOH}$ terminus (GFP::DAT-1 $(\Delta 25)$ ), however, lead to almost complete intracellular retention with little transport to terminals or dendrites. These findings are the first to our knowledge to support a role for cytoplasmic sequences in the trafficking and function of DAT proteins in vivo and form the starting point for a directed effort to uncover the specific sequences in the $\Delta 25$ region, that, along with their binding partners, establish appropriate DAT-1 localization and ultimately appropriate in vivo DA clearance capacity. These studies also suggest that synaptically targeted DAT- 1 protein is critical for limiting DA suppression of motor activity, consistent with coordinated DA release, response and inactivation in the nematode in vivo.

\section{References}

Ahmari SE, Buchanan J, Smith SJ (2000) Assembly of presynaptic active zones from cytoplasmic transport packets. Nat Neurosci 3:445-451.

Altun ZF, Hall DH (2005) Handbook of C. elegans anatomy. In: WormAtlas. E-book available at http://www.wormatlas.org/handbook/ contents.htm.

Bannon MJ, Poosch MS, Xia Y, Goebel DJ, Cassin B, Kapatos G (1992) Dopamine transporter mRNA content in human substantia nigra decreases precipitously with age. Proc Natl Acad Sci USA 89:7095-7099.

Barstead RJ, Kleiman L, Waterston RH (1991) Cloning, sequencing, and mapping of an alpha-actinin gene from the nematode Caenorhabditis elegans. Cell Motil Cytoskeleton 20:69-78.

Benoit-Marand M, Jaber M, Gonon F (2000) Release and elimination of dopamine in vivo in mice lacking the dopamine transporter: functional consequences. Eur J Neurosci 12:2985-2992.

Bjerggaard C, Fog JU, Hastrup H, Madsen K, Loland CJ, Javitch JA, Gether U (2004) Surface targeting of the dopamine transporter involves discrete epitopes in the distal $\mathrm{C}$ terminus but does not require canonical PDZ domain interactions. J Neurosci 24:7024-7036.

Brenner S (1974) The genetics of Caenorhabditis elegans. Genetics 77:71-94 Campbell RE, Tour O, Palmer AE, Steinbach PA, Baird GS, Zacharias DA, Tsien RY (2002) A monomeric red fluorescent protein. Proc Natl Acad Sci USA 99:7877-7882.

Carlsson ML, Carlsson A, Nilsson M (2004) Schizophrenia: from dopamine to glutamate and back. Curr Med Chem 11:267-277. 
Carneiro AM, Ingram SL, Beaulieu JM, Sweeney A, Amara SG, Thomas SM, Caron MG, Torres GE (2002) The multiple LIM domain-containing adaptor protein Hic-5 synaptically colocalizes and interacts with the dopamine transporter. J Neurosci 22:7045-7054.

Carvelli L, McDonald PW, Blakely RD, Defelice LJ (2004) Dopamine transporters depolarize neurons by a channel mechanism. Proc Natl Acad Sci USA 101:16046-16051.

Chase DL, Pepper JS, Koelle MR (2004) Mechanism of extrasynaptic dopamine signaling in Caenorhabditis elegans. Nat Neurosci 7:1096-1103.

Ciliax BJ, Drash GW, Staley JK, Haber S, Mobley CJ, Miller GW, Mufson EJ, Mash DC, Levey AI (1999) Immunocytochemical localization of the dopamine transporter in human brain. J Comp Neurol 409:38-56.

Clark SG, Chiu C (2003) C. elegans ZAG-1, a Zn-finger-homeodomain protein, regulates axonal development and neuronal differentiation. Development 130:3781-3794.

Crossman AR, Clarke CE, Boyce S, Robertson RG, Sambrook MA (1987) MPTP-induced parkinsonism in the monkey: neurochemical pathology, complications of treatment and pathophysiological mechanisms. Can J Neurol Sci 14:428-435.

Dani JA, Zhou FM (2004) Selective dopamine filter of glutamate striatal afferents. Neuron 42:522-524.

Duerr JS, Frisby DL, Gaskin J, Duke A, Asermely K, Huddleston D, Eiden LE, Rand JB (1999) The cat-1 gene of Caenorhabditis elegans encodes a vesicular monoamine transporter required for specific monoaminedependent behaviors. J Neurosci 19:72-84.

Erickson JD, Eiden LE, Hoffman BJ (1992) Expression cloning of a reserpine-sensitive vesicular monoamine transporter. Proc Natl Acad Sci USA 89:10993-10997.

Farhan H, Korkhov VM, Paulitschke V, Dorostkar MM, Scholze P, Kudlacek O, Freissmuth M, Sitte HH (2004) Two discontinuous segments in the carboxyl terminus are required for membrane targeting of the rat gammaaminobutyric acid transporter-1 (GAT1). J Biol Chem 279:28553-28563.

Ferguson SM, Savchenko V, Apparsundaram S, Zwick M, Wright J, Heilman CJ, Yi H, Levey AI, Blakely RD (2003) Vesicular localization and activity-dependent trafficking of presynaptic choline transporters. J Neurosci 23:9697-9709.

Finney M, Ruvkun G (1990) The unc-86 gene product couples cell lineage and cell identity in C. elegans. Cell 63:895-905.

Fiorino DF, Coury A, Fibiger HC, Phillips AG (1993) Electrical stimulation of reward sites in the ventral tegmental area increases dopamine transmission in the nucleus accumbens of the rat. Behav Brain Res 55:131-141.

Foster JD, Cervinski MA, Gorentla BK, Vaughan RA (2006) Regulation of the dopamine transporter by phosphorylation. Handb Exp Pharmacol 197-214.

Gainetdinov RR, Jones SR, Fumagalli F, Wightman RM, Caron MG (1998) Re-evaluation of the role of the dopamine transporter in dopamine system homeostasis. Brain Res Brain Res Rev 26:148-153.

Gainetdinov RR, Sotnikova TD, Caron MG (2002) Monoamine transporter pharmacology and mutant mice. Trends Pharmacol Sci 23:367-373.

Giros B, Jaber M, Jones SR, Wightman RM, Caron MG (1996) Hyperlocomotion and indifference to cocaine and amphetamine in mice lacking the dopamine transporter. Nature 379:606-612.

Hall DH, Hedgecock EM (1991) Kinesin-related gene unc-104 is required for axonal transport of synaptic vesicles in C. elegans. Cell 65:837-847.

Hayashi Y, Shi SH, Esteban JA, Piccini A, Poncer JC, Malinow R (2000) Driving AMPA receptors into synapses by LTP and CaMKII: requirement for GluR1 and PDZ domain interaction. Science 287:2262-2267.

Hernandez L, Hoebel BG (1988) Food reward and cocaine increase extracellular dopamine in the nucleus accumbens as measured by microdialysis. Life Sci 42:1705-1712.

Hironaka N, Ikeda K, Sora I, Uhl GR, Niki H (2004) Food-reinforced operant behavior in dopamine transporter knockout mice: enhanced resistance to extinction. Ann NY Acad Sci 1025:140-145.

Hoffman BJ, Hansson SR, Mezey E, Palkovits M (1998) Localization and dynamic regulation of biogenic amine transporters in the mammalian central nervous system. Front Neuroendocrinol 19:187-231.

Holton KL, Loder MK, Melikian HE (2005) Nonclassical, distinct endocytic signals dictate constitutive and PKC-regulated neurotransmitter transporter internalization. Nat Neurosci 8:881-888.

Jayanthi LD, Apparsundaram S, Malone MD, Ward E, Miller DM, Eppler M, Blakely RD (1998) The Caenorhabditis elegans gene T23G5.5 encodes an antidepressant- and cocaine-sensitive dopamine transporter. Mol Pharmacol 54:601-609.

Kim CH, Takamiya K, Petralia RS, Sattler R, Yu S, Zhou W, Kalb R, Wenthold R, Huganir R (2005) Persistent hippocampal CA1 LTP in mice lacking the C-terminal PDZ ligand of GluR1. Nat Neurosci 8:985-987.

Kornau HC, Seeburg PH, Kennedy MB (1997) Interaction of ion channels and receptors with PDZ domain proteins. Curr Opin Neurobiol 7:368-373.

Lints R, Emmons SW (1999) Patterning of dopaminergic neurotransmitter identity among Caenorhabditis elegans ray sensory neurons by a TGFbeta family signaling pathway and a Hox gene. Development 126:5819-5831.

Loder MK, Melikian HE (2003) The dopamine transporter constitutively internalizes and recycles in a protein kinase C-regulated manner in stably transfected PC12 cell lines. J Biol Chem 278:22168-22174.

Lorang D, Amara SG, Simerly RB (1993) Cell-type specific expression of catecholamine transporters in the rat brain. J Neurosci 14:4903-4914.

Madsen KL, Beuming T, Niv MY, Chang CW, Dev KK, Weinstein H, Gether U (2005) Molecular determinants for the complex binding specificity of the PDZ domain in PICK1. J Biol Chem 280:20539-20548.

Matthies DS, Fleming PA, Wilkes DM, Blakely RD (2006) The Caenorhabditis elegans choline transporter $\mathrm{CHO}-1$ sustains acetylcholine synthesis and motor function in an activity-dependent manner. J Neurosci 26:6200-6212.

McDonald PW, Jessen T, Field JR, Blakely RD (2006) Dopamine signaling architecture in Caenorhabditis elegans. Cell Mol Neurobiol 26:593-618.

Medvedev IO, Gainetdinov RR, Sotnikova TD, Bohn LM, Caron MG, Dykstra LA (2005) Characterization of conditioned place preference to cocaine in congenic dopamine transporter knockout female mice. Psychopharmacology (Berl) 180:408-413.

Melikian HE (2004) Neurotransmitter transporter trafficking: endocytosis, recycling, and regulation. Pharmacol Ther 104:17-27.

Mello CC, Kramer JM, Stinchcomb D, Ambros V (1991) Efficient gene transfer in C. elegans: extrachromosomal maintenance and integration of transforming sequences. EMBO J 10:3959-3970.

Miles PR, Mundorf ML, Wightman RM (2002) Release and uptake of catecholamines in the bed nucleus of the stria terminalis measured in the mouse brain slice. Synapse 44:188-197.

Miller III DM, Niemeyer CJ (1995) Expression of the unc-4 homeoprotein in Caenorhabditis elegans motor neurons specifies presynaptic input. Development 121:2877-2886.

Miranda M, Sorkina T, Grammatopoulos TN, Zawada WM, Sorkin A (2004) Multiple molecular determinants in the carboxyl terminus regulate dopamine transporter export from endoplasmic reticulum. J Biol Chem 279:30760-30770.

Nass R, Hall DH, Miller III DM, Blakely RD (2002) Neurotoxin-induced degeneration of dopamine neurons in Caenorhabditis elegans. Proc Natl Acad Sci USA 99:3264-3269.

Nass R, Hahn MK, Jessen T, McDonald PW, Carvelli L, Blakely RD (2005) A genetic screen in Caenorhabditis elegans for dopamine neuron insensitivity to 6-hydroxydopamine identifies dopamine transporter mutants impacting transporter biosynthesis and trafficking. J Neurochem 94:774-785.

Nirenberg MJ, Chan J, Vaughan RA, Uhl GR, Kuhar MJ, Pickel VM (1997a) Immunogold localization of the dopamine transporter: an ultrastructural study of the rat ventral tegmental area. J Neurosci 17:5255-5262.

Nirenberg MJ, Chan J, Pohorille A, Vaughan RA, Uhl GR, Kuhar MJ, Pickel VM (1997b) The dopamine transporter: comparative ultrastructure of dopaminergic axons in limbic and motor compartments of the nucleus accumbens. J Neurosci 17:6899-6907.

Nonet ML, Grundahl K, Meyer BJ, Rand JB (1993) Synaptic function is impaired but not eliminated in C. elegans mutants lacking synaptotagmin. Cell 73:1291-1305.

Nonet ML, Saifee O, Zhao H, Rand JB, Wei L (1998) Synaptic transmission deficits in Caenorhabditis elegans synaptobrevin mutants. J Neurosci 18:70-80.

Powell SB, Lehmann-Masten VD, Paulus MP, Gainetdinov RR, Caron MG, Geyer MA (2004) MDMA "ecstasy" alters hyperactive and perseverative behaviors in dopamine transporter knockout mice. Psychopharmacology (Berl) 173:310-317.

Ranganathan R, Sawin ER, Trent C, Horvitz HR (2001) Mutations in the Caenorhabditis elegans serotonin reuptake transporter MOD-5 reveal 
serotonin-dependent and -independent activities of fluoxetine. J Neurosci 21:5871-5884.

Reimherr FW, Wender PH, Ebert MH, Wood DR (1984) Cerebrospinal fluid homovanillic acid and 5-hydroxy-indoleacetic acid in adults with attention deficit disorder, residual type. Psychiatry Res 11:71-78.

Rodriguiz RM, Chu R, Caron MG, Wetsel WC (2004) Aberrant responses in social interaction of dopamine transporter knockout mice. Behav Brain Res 148:185-198.

Sanyal S, Wintle RF, Kindt KS, Nuttley WM, Arvan R, Fitzmaurice P, Bigras E, Merz DC, Hebert TE, van der Kooy D, Schafer WR, Culotti JG, Van Tol HH (2004) Dopamine modulates the plasticity of mechanosensory responses in Caenorhabditis elegans. EMBO J 23:473-482.

Sawin ER, Ranganathan R, Horvitz HR (2000) C. elegans locomotory rate is modulated by the environment through a dopaminergic pathway and by experience through a serotonergic pathway. Neuron 26:619-631.

Schafer WR, Kenyon CJ (1995) A calcium-channel homologue required for adaptation to dopamine and serotonin in Caenorhabditis elegans. Nature 375:73-78.

Seamans JK, Yang CR (2004) The principal features and mechanisms of dopamine modulation in the prefrontal cortex. Prog Neurobiol 74:1-58.
Sulston J, Dew M, Brenner S (1975) Dopaminergic neurons in the nematode Caenorhabditis elegans. J Comp Neurol 163:215-226.

Terskikh A, Fradkov A, Ermakova G, Zaraisky AG, Tan P, Kajava AV, Zhao X, Lukyanov S, Matz M, Kim S, Weissman I, Siebert P (2000) "Fluorescent timer": protein that changes color with time. Science 290:1585-1588.

Tillerson JL, Caudle WM, Parent JM, Gong C, Schallert T, Miller GW (2006) Olfactory discrimination deficits in mice lacking the dopamine transporter or the D2 dopamine receptor. Behav Brain Res 172:97-105.

Torres GE, Yao WD, Mohn RR, Quan H, Kim K, Levey AI, Staudinger J, Caron MG (2001) Functional interaction between monoamine plasma membrane transporters and the synaptic PDZ domain-containing protein PICK1. Neuron 30:121-134.

White JG, Southgate E, Thompson JN, Brenner S (1986) The structure of the nervous system of the nematode Caenorhabditis elegans. Philos Trans R Soc Lond B Biol Sci 314:1-340.

Williams BD, Schrank B, Huynh C, Shownkeen R, Waterston RH (1992) A genetic mapping system in Caenorhabditis elegans based on polymorphic sequence-tagged sites. Genetics 131:609-624.

Zhai RG, Vardinon-Friedman H, Cases-Langhoff C, Becker B, Gundelfinger ED, Ziv NE, Garner CC (2001) Assembling the presynaptic active zone: a characterization of an active one precursor vesicle. Neuron 29:131-143. 